\title{
PANTULAN (REFLEKS) PROTO AUSTRONESIA (PAN) KE PROTOBAHASA KABOLA, PROTOBAHASA HAMAP, DAN PROTOBAHASA KLON DI PULAU ALOR, NUSA TENGGARA TIMUR
}

\author{
Ida Ayu Iran Adhiti \\ IKIP PGRI Bali \\ dayuiran@gmail.com
}

\begin{abstract}
ABSTRAK
Pendataan terhadap bahasa-bahasa daerah di wilayah Nusa Tenggara Timur perlu dikaji, terutama bahasa-bahasa daerah di Pulau Alor. Peneliti mengkaji pendataan terhadap bahasa Kabola, bahasa Hamap, dan bahasa Klon dengan kajian linguistik historis komparatif. Penelitian ini menggunakan pendekatan sinkronik, untuk mengetahui perkembangan bahasa pada satu kurun waktu. Kajian ini didasarkan pada hasil rekonstruksi PAN dari para ahli seperti: Demwolff, Dyen, Blust, Lopez, disusun pada daftar rekonstruksi bahasa Austronesia yang disusun oleh Wurm dan Wilson. Metode perbandingan yang digunakan pada penelitian ini bersifat sinkomparatif, untuk menemukan ciri-ciri kesamaan dan perbedaan antarbahasa kerabat yang hidup pada masa yang sama. Fenomena kebahasaan yang dikaji bersifat deskriptif, yakni data yang dikumpulkan adalah data pada masa sekarang.Pantulan (refleks) PAN ke Protobahasa Kabola, Hamap, dan Klon (PKbHpKl) ditemukan refleks fonem vokal PAN, deret vokal PAN, fonem konsonan PAN, dan gugus konsonan PAN pada PKbHpKl. Beberapa fonem yang terpantul dari Proto PAN ke protobahasa Kabola, protobahasa Hamap, dan protobahasa Klon menunjukkan bahwa ketiga bahasa tersebut merupakan turunan dari Proto PAN serta tergolong bahasa Austronesia.
\end{abstract}

Kata kunci: pantulan dan Linguistik Historis Komparatif.

\begin{abstract}
[Title: The reflexion of proto Austronesia to Kabola, Hamap, and Klon protolanguage in Alor Island, Nusa Tenggara Timurl Making data of the local languages in Nusa Tenggara Timur need to be observed, especially the local languages in Alor Island. The observer analyses the data collection in the languages of Kabola, Hamap, and Klon by the study of comparative historic linguistic. This observation uses synchronous approach, to know the language development in a period. This study is based on the result of PAN reconstruction of experts, such as: Demwolff, Dyen, Blust, Lopez, compiled by the list of Austronesia reconstruction composed by Wurm and Wilson. Comparative method used in this observation is sin comparative, to find the characteristics of similarity and the difference between relative languages that are alive in the same period. The language phenomena that is analysed is descriptive, firstly the data that is collected is the data of nowdays period. Reflection of PAN to Protolanguage Kabola, Hamap, and Klon ( $\mathrm{PKbHpKl}$ ) are found reflection of vocal phoneme PAN, vocal series of PAN, consonant phoneme of PAN, and cluster of consonant PAN on PKbHpKl. Some phonemes are reflected from Proto PAN to Protolanguage Kabola, Hamap, and Klon show that the three languages are derivativeof Proto PAN and Austronesia.
\end{abstract}

Keyword: reflection and comparative historic linguistic 


\section{PENDAHULUAN}

Setiap bahasa memiliki ciri tertentu yang terdapat pula dalam bahasabahasa lain. Para linguis diharapkan mampu menguasai secara reseptif satu atau lebih beberapa bahasa lain di samping bahasanya sendiri. Bahasa yang dikuasai tersebut tidak serumpun dengan bahasanya sendiri. Bahasa manusia didasari oleh khasanah dasar yang juga tampak terisolasi secara biologis. Khasanah bahasa yang tidak terbatas memiliki ciri-ciri tersendiri, ditunjukkan dalam bentuk murni pada angka alami. (Verhaar, 1984:6 dalam Chomsky, 2000 :3).

Sejarah bahasa dapat dipelajari dengan dua cara atau dua arah seperti penayangan video yang dimainkan maju atau mundur. Studi tentang sejarah bahasa merupakan kajian tentang perubahan bahasa dengan rekonstruksi setiap bahasa. Ahli bahasa memulai rekonstruksi dengan data awal yang tersedia dari keluarga bahasa, baik tertulis maupun lisan serta memastikan tahap-tahap awal dari bahasa atau nenek moyang bahasa. Bahasa Proto-Indo-Eropa dapat ditelusuri kembali dan diproyeksikan, walaupun tidak memiliki teks dan tidak ada penutur, selalu bergantung pada rekonstruksi komparatif (McMahon, 1999: 6).

Perbandingan antara dua bahasa atau lebih dapat dikatakan sama usianya dengan timbulnya ilmu bahasa itu sendiri. Pemahaman tentang suatu bahasa selalu menarik_perhatian orang untuk mengetahui sejauh mana terdapat kesamaan atau kemiripan aspek bahasa tersebut. Pendekatan tersebut dimulai dengan unsurunsur kata, perlahan-lahan berkembang terus menuju perbandingan yang lebih kompleks. Linguistik komparatif atau linguistik bandingan merupakan suatu cabang dari ilmu bahasa (linguistik) yang berusaha untuk meletakkan dasar-dasar pengertian tentang perkembangan kesejarahan dan kekerabatan antara bahasabahasa di dunia. Pengaruh timbal balik dari unsur-unsurnya dikaji, terutama terhadap bahasa yang pernah melakukan kontak dalam sejarah (Keraf, 1990:1).

Keluarga bahasa Austronesia memiliki sekitar 1.200 bahasa, yang bersama -sama dituturkan oleh sekitar 270 juta orang. Dapat dikatakan, bahwa bahasa Austronesia merupakan rumpun bahasa terbesar, terutama dalam hal penyebaran geografis setelah rumpun bahasa Indo-Eropa. Bahasa Austronesia tersebar dari Malagasi (di Madagaskan dan di Pulau Mayotte) di bagian barat Samudra Hindia ke Rapanui atau Pulau Paskah di bagian tenggara Samudera Pasifik. Dengan demikian, secara tradisional bahasa ditemukan berdasarkan penyelidikan serta adanya kontak bahasa rumpun Austronesia yang terpisah secara geografis, seperti: negara, kepulauan, sungai, pantai, dan sebagainya. Sejak dekolonisasi ada kecenderungan digantikan oleh bahasa nasional yang baru dibentuk, yakni bahasa Indonesia, Malaysia, Pilipina, Thailand, Vietnam, dan sebagainya (Adelaar, $2005: 1)$.

Rumpun bahasa Austronesia membentuk rumpun bahasa yang memiliki keterkaitan erat, seperti Austoasiatik, Uto-Aztecan, dan Indo-Eropa. Bahasa Austronesia memiliki wilayah paling luas di dunia, dari Madagaskar ke Pulau Paskah. Beberapa lama kemudian berkembang di Indonesia, Malaysia, Filipina, dan Madagaskar (Bellwood Peter; James J.Fox; Darerll Tryon, 1995: 1-19).

Beberapa karya tulis yang mengkaji tentang bahasa daerah di Nusa Tenggara Timur dengan pendekatan Linguistik Historis Komparatif disajikan sebagai berikut.

"Kelompok Bahasa Bima-Sumba, Kajian Linguistik Historis Komparatif" dikaji dalam bentuk disertasi. Kajian tersebut membahas tentang sekilas pandang bahasa-bahasa kelompok Bima-Sumba. Bahasa-bahasa yang termasuk kelompok 
Bima-Sumba adalah bahasa Bima (BM), bahasa Komodo (KM), bahasa Manggarai (MG), bahasa Ngada (Ng), bahasa Lio (Li), bahasa Sumba (SB), dan bahasa Sawu (SW) (Syamsudin, 1996). Pengolahan data dilakukan dengan pendekatan kuantitatif dan kualitatif. Rekonstruksi terhadap protobahasa dilakukan untuk menentukan kemiripan kosakata pokok, penentuan masa pisah, serta pengelompokan bahasa. "Relasi Historis Kekerabatan Bahasa Flores (Kajian Linguistik Historis Komparatif Terhadap Sembilan Bahasa di Flores)" merupakan penelitian bahasa yang disajikan dalam bentuk disertasi (Fernandez, 1996). Keadaan bahasa -bahasa di Flores diuraikan secara mendalam untuk mengelompokkan sembilan bahasa yang diteliti yakni bahasa Manggarai, bahasa Komodo, bahasa Rembong, bahasa Ngada, bahasa Lio, bahasa Palu'e, bahasa Sikka, bahasa Lamaholot, dan bahasa Kedang. Rekonstruksi leksikal ditemukan sejumlah etimon protobahasa Flores yang memperkuat keyakinan adanya kelompok bahasa Flores tersebut. Selanjutnya dikaji rekonstruksi protobahasa Flores Barat dan Flores Timur serta rekonstruksi protobahasa Austronesia ke proto Flores. Hasil penelitian ditemukan bahwa kelompok bahasa Flores merupakan anggota kelompok bahasa Austronesia tengah. "Kekerabatan Bahasa-Bahasa Sumba: Suatu Kajian Linguistik Komparatif. Kajian ini membahas tentang bahasa-bahasa di Pulau Sumba yakni: bahasa Kodi, bahasa Weweha, bahasa Laboya, bahasa Kambera, bahasa Mamboro, bahasa Wanokaka, dan bahasa Anakalang (Budasi, 2007). Metode yang dilakukan adalah metode diakronis dengan teknik leksikostatistik dan teknik rekonstruksi. Hasil penelitian menunjukkan bahwa ketujuh bahasa tersebut memiliki hubungan kekerabatan yang erat. Penelitian juga dilakukan di Pulau Kaisar Maluku Tenggara dan Timor Leste mengenai hubungan evolusi fonologis bahasa Oirata dan kekerabatannya dengan bahasa-bahasa non-Austronesia di Timor Leste (Mandala, 1999). Berdasarkan bukti-bukti linguistik yang tercermin dalam sejumlah besar kata berkerabat diindikasikan bahwa bahasa Oirata sebagai bahasa non-Austronesia yang berkerabat dengan bahasa-bahasa di Timor Leste yaitu bahasa Bunak, bahasa Makasai, bahasa Fataluku, dan bahasa Lovaea. Penelitian dilakukan dalam bentuk disertasi tentang "Protobahasa Modebur, Kaera, Dan Teiwa, Bahasa Kerabat Non Austronesia Di Pulau Pantar Nusa Tenggara Timur" (Ino, 2013). Penelitian dengan kajian linguistik historis komparatif menyasar pada bahasa-bahasa yang ada di Pulau Pantar. Data bahasa dikumpulkan dengan wawancara dan cakap semuka. Analisis data menggunakan metode sinkomparatif dan diakomparatif. Berdasarkan bukti kuantitatif ditemukan dua kelompok bahasa yaitu bahasa Austronesia dan non-Austronesia.

Beberapa penelitian di atas mengkaji tentang bahasa-bahasa daerah di wilayah Nusa Tenggara Timur (NTT), kajian linguistik historis komparatif dengan pendekatan kuantitatif dan kualitatif. Penelitian yang dilakukan bersifat sinkomparatif dan diakomparatif, dengan mengkaji sejarah bahasa pada satu kurun waktu dan beberapa kurun waktu. Perbedaan dengan penelitian penulis terletak pada bentuk analisis dan objek penelitiannya.Temuan yang diperoleh tentu berbeda dengan penelitian sebelumnya, sehingga dapat memberikan kontribusi terhadap penelitian selanjutnya. Peneliti mengkaji tiga bahasa daerah di Pulau Alor yakni bahasa Kabola, bahasa Hamap, dan bahasa Klon mengenai jumlah etimon ketiga bahasa tersebut dan pantulan (refleks) Proto Austronesia (PAN) ke protobahasa Kabola, protobahasa Hamap, dan protobahasa Klon. 


\section{METODE}

Penelitian bahasa Kabola berlokasi di Desa Lendola, Teluk Mutiara, Kecamatan Alor Barat Laut. Penelitian bahasa Hamap berlokasi di Desa Moru Kecamatan Alor Barat Daya. Selanjutnya, penelitian bahasa Klon berlokasi di Desa Probur, Kecamatan Alor Barat Daya.

Sumber data dalam penelitian ini terdiri atas sumber data primer dan sumber data sekunder. Sumber data primer diperoleh dari sejumlah penutur asli yang dipakai sebagai informan. Sedangkan sumber data sekunder diperoleh dari kajian yang ditulis dari beberapa pakar. Penentuan informan sesuai dengan persyaratan (Samarin, 1998: 55-70 band dengan Suryati, 2012 : 61). Jumlah informan di lokasi penelitian pada masing-masing bahasa minimal 3 orang. Apabila ada informan yang sudah ditentukan, tetapi data yang diperoleh meragukan maka dilakukan pengecekan langsung terhadap pemakai bahasa tersebut. Data bahasa yang digali menggunakan 1.500 kosakata daftar Holle.

Instrumen penelitian yang digunakan ada dua macam yaitu istrumen untuk menggali data kebahasaan dan nonkebahasaan. Data kebahasaan dipaparkan berupa 1500 kosakata dari daftar Holle. Daftar pertanyaan memuat tentang konstruksi kata, seperti kelompok kata keadaan, kata bilangan, kata kekerabatan, kata sifat, kata-kata yang tergolong mata pencaharian dan sebagainya. Penjaringan data tersebut dibantu dengan teknik perekaman cerita rakyat atau dongeng untuk mengecek kebenaran data. Beberapa instrumen yang mendukung penelitian adalah camera, tape recorder, serta kartu pencatatan yang digunakan saat penelitian. Untuk memperoleh data yang akurat juga didukung dengan menampilkan beberapa gambar, peragaan, atau aktivitas lainnya agar lebih mudah dipahami. Data nonkebahasaan pada penelitian menggali gambaran umum tentang ketiga bahasa serta keberadaannya di masyarakat.

Metode pupuan lapangan (Ayatrohaedi, 1979: 33) dapat digunakan untuk memperoleh data di daerah penelitian. Metode ini dapat dijabarkan menjadi metode simak dan metode cakap (band dengan Sudaryanto, 1986: 2 - 9); (Mashun, 2007 :92-96). Istilah observasi untuk metode simak dan wawancara untuk istilah metode cakap (cakap semuka) (Bungin, 2008).

Metode observasi digunakan untuk melakukan pengamatan di lokasi penelitian, agar memperoleh gambaran secara utuh dan menyeluruh mengenai fenomena kebahasaan yang sedang diamati (Muhajir. Noeng H, 1996 :180). Sedangkan metode wawancara dilakukan dengan cara menanyakan sesuatu kepada informan serta tanya jawab dan tatap muka dengan informan (Danandjaya, 1994:102). Metode pengumpulan data dengan wawancara menggunakan 1.500 kosakata daftar Holle

Tahapan penganalisisan data, peneliti menggunakan metode deskriptif analitis yakni mendeskripsikan bahasa-bahasa di daerah penelitian dari 1.500 kosakata daftar Holle yang disebar kepada informan. Teknik lanjutannya adalah teknik hubung banding, baik hubung banding membedakan maupun menyamakan (Sudaryanto, 1986 :13-30); (Djajasudarma, 1993 :58); dan (Mashun, 2007 :120122).

Metode yang dipakai dalam menyajikan hasil penelitian ini adalah metode formal dan informal serta kombinasi antara formal dan informal. Metode formal adalah perumusan dengan tanda dan lambang-lambang. Tanda yang dimaksud seperti: tanda /..../ menunjukkan ejaan fonemis; tanda (*) tanda bintang, menunjukkan proto; tanda panah $(\rightarrow)$ tanda arah perubahan; tanda kurung biasa $(())$; 
kurung kurawal ( \{\}$)$; dan sebagainya. Metode informal yang dimaksud adalah adalah penyajian hasil analisis dengan untaian kata-kata agar penjelasannya terurai dan terinci (Sudaryanto, 1986:45).

\section{PEMBAHASAN}

Bahasa-bahasa daerah di Kabupaten Alor memiliki keunikan tersendiri, jika diamati dari segi keberadaannya dan kuantitas rumpun bahasanya. Meskipun mempunyai jarak tempat tinggal cukup dekat antara salah satu suku dengan suku lainnya, terdapat perbedaan bahasa. Keanekaragaman bahasa daerahnya mempunyai pengaruh yang sangat besar pada kehidupan bermasyarakat. Menurut penelitian La Ino ada dua kelompok bahasa yang hidup di Nusa Tenggara Timur (NTT), yakni satu kelompok bahasa yang tergolong bahasa Austronesia dan 12 bahasa non-Austronesia (La Ino, 2013 :6). Berdasarkan pendataan Dinas Pendidikan dan Kebudayaan Kabupaten Alor terdapat 18 bahasa daerah. Bahasa-bahasa daerah tersebut adalah: (1) Bahasa Daerah Alores; (2) Bahasa Daerah Kabola/ Adang; (3) Bahasa Daerah Abui/A'fui; (4) Bahasa Daerah Hamap; (5) Bahasa Daerah Klon; (6) Bahasa Daerah Kui; (7) Bahasa Daerah Kafoa; (8) Bahasa Daerah Panea; (9) Bahasa Daerah Kamang; (10) Bahasa Daerah Kailesa; (11) Bahasa Daerah Wersin/Kula; (12) Bahasa Daerah Talangpui/Sawila; (13) Bahasa Daerah Blagar/Pura; (14) Bahasa Daerah Retta; (15) Bahasa Daerah Taiwa; (16) Bahasa Daerah Nedebang/Bintang/Kalamu; (17) Bahasa Daerah Deing/Diang; dan (18) Bahasa Daerah Lamma. Ditinjau dari klasifikasi daerah penyebaran dan luas pemakainya, dikelompokkan menjadi bahasa daerah terbesar, menengah, dan terkecil (Retika, 2012:1--10).

Penelusuran perkembangan Proto Austronesia (PAN) terhadap penelusuran protobahasa Kabola, protobahasa Hamap, dan protobahasa Klon ( $\mathrm{PKbHpKl})$ menampakkan adanya kesejajaran terhadap perkembangan ketiga bahasa tersebut. Kesejajaran dan perkembangannya tampak berupa sejumlah fonem yang dapat ditelusuri kembali ke tahap awal. Perkembangan serta perubahan fonem yang berkorespondensi secara teratur dan wajar terdapat pada protobahasa Kabola, protobahasa Hamap, dan protobahasa Klon ( $\mathrm{PKbHpKl)} \mathrm{dalam} \mathrm{kajian} \mathrm{per-}$ bandingan $\mathrm{PKbHpKl}$. Selanjutnya diuraikan tentang perbandingan kajian protofonem PAN terhadap $\mathrm{PKbHpKl}$, menyangkut perubahan protofonem yang teratur dan tidak teratur.

Berikut ini disajikan daftar etimon protobahasa Kabola, protobahasa Hamap, dan protobahasa Klon $(\mathrm{PKbHpKl})$. Selanjutnya diuraikan mengenai pantulan (refleks) Proto Austronesia (PAN) ke Protobahasa Kabola, Hamap, dan Klon (PKbHpKl). Berturut-turut dipaparkan tentang pantulan (refleks) fonem PAN pada Protobahasa Kabola, Hamap, dan Klon (PKbHpKl) yakni pantulan (refleks) fonem vokal PAN pada PKbHpKl, pantulan (refleks) deret vokal PAN pada PKbHpKl, pantulan (refleks) fonem konsonan PAN pada PKbHpK1, pantulan (refleks) deret konsonan PAN pada $\mathrm{PKbHpKl}$, serta pantulan (refleks) gugus konsonan PAN pada PKbHpKl.

\section{Daftar Etimon Protobahasa}

Daftar etimon protobahasa Kabola, protobahasa Hamap, dan protobahasa Klon (PKbHpKl) disajikan data pada glos yang disusun secara alphabetis. Rujukan nama yang menyusun bentuk PAN disertakan setelah PAN, diawali dengan tanda garis miring (/) seperti: PAN/D adalah Proto-Austronesian menurut 
Denpwolff, 1938; PAN/C adalah Proto-Austronesian menurut Capell, 1943;

PAN/POCMI adalah Proto-Oceanic menurut MILKE 1968; PAWLEY, dan sebagainya.
1. *naba 'apa'
$\mathrm{PKb}-\mathrm{Hp}-\mathrm{Kl}$ *naba
2. *hiual 'ayam betina'
$\left(\mathrm{PAN} / \mathrm{POCMI} *_{z a b a}\right)$
3. *ul PKb-Hp-Kl *hiu al
$\mathrm{PKb}-\mathrm{Hp}-\mathrm{Kl} * u l$
4. *boi 'babi'
$\mathrm{PKb}-\mathrm{Hp}-\mathrm{Kl} \quad *$ boi
5. *bagai 'buaya'
6. *fetay
PKb-Hp-Kl *bagai
7. *marne-Hp-K1 *fetay
7. *marne
'cecak'
*marne
'cabut' (PAN/ PPHCA *fenen $)$
8. *med $\mathrm{PKb}-\mathrm{Hp}-\mathrm{K} 1$
$(\mathrm{PAN} / \mathrm{PPNBIWO}$ * marko)
9. *mih
$\mathrm{PKb}-\mathrm{Hp}-\mathrm{K} 1$
'dapat'
$\mathrm{PKb}-\mathrm{Hp}-\mathrm{K} 1$
10. *mamay
$\mathrm{PKb}-\mathrm{Hp}-\mathrm{Kl}$
11. *arfah
PKb-Hp-K1
*med
'duduk'
12. *mol
*mih
'duri'
*mamay
'dagu'
*arfah
'dalam'
13. $* d a$
$\mathrm{PKb}-\mathrm{Hp}-\mathrm{Kl}$
*mol
'depa'
$\mathrm{PKb}-\mathrm{Hp}-\mathrm{K}$
$* d a$
14. *dai
PKb-Hp-K1
'hampir'
(PAN/ FOWL *hui pa)
(PAN/D *vulan)
(PAN/ PANS *babuy)
(PAN/ POCMI *buaya)
(PAN/ PPHZA *seped)
$(\mathrm{PAN} / \mathrm{PWPPAW} * m i a)$
(PAN/ PAMS *mamay)
(PAN/ C *ajay)
(PAN/ BLWO *lom)
$(\mathrm{PAN} / \mathrm{D} *$ depa $)$
(PAN/ PSOPNPAWS * tei)
*dai
'ikan'
$\mathrm{PKb}-\mathrm{Hp}-\mathrm{Kl}$
$* a b$
16. *bate
'jagung'
17. *odi
PKb-Hp-K1
*bate
$\mathrm{PKb}-\mathrm{Hp}-\mathrm{K}$
'jika'
18. *taboi
PKb-Hp-K1
*odi
'kepiting'
*taboi
19. *tanem
PKb-Hp-K1
'mengubur'
20. *tinaak
*tanem
'menipu'
21. *na
$\mathrm{PKb}-\mathrm{Hp}-\mathrm{Kl}$
*tinaak
'minum'
PKb-Hp-K1
$*_{n a}$
22. *da om
PKb-Hp-K1
23. *tapora 'menantu'
*daom
'menawar'
*tapora
(PAN/D *a'uk)
(PAN/ D *buti)
$(\mathrm{PAN} / \mathrm{LO} *$ ona $)$
$(\mathrm{PAN} / \mathrm{D} *$ tambak $)$
(PAN/ D *tanem)
(PAN/ D *tipuh)
$(\mathrm{PAN} / \mathrm{D} * n a)$
$(\mathrm{PAN} / \mathrm{POCGR} * d a u w a)$
(PAN/ BLWO *tauwa) 


\begin{tabular}{|c|c|c|}
\hline 24. *esah & 'mencret' & $(\mathrm{PAN} / \mathrm{BLAA} * k e a h)$ \\
\hline Pkb-Hp-K1 & *keah & \\
\hline 25. *dafay & 'obat' & $(\mathrm{PAN} / \mathrm{D} *$ taqay $)$ \\
\hline $\begin{array}{l}\text { PKb-Hp-Kl } \\
\text { 26. }{ }_{\text {gopot }}\end{array}$ & $\begin{array}{l}\text { *dafay } \\
\text { 'paha' }\end{array}$ & (PAN/ D *gopot) \\
\hline * $\mathrm{PKb}-\mathrm{Hp}-\mathrm{Kl}$ & *gopot & $(\mathrm{PAN} / \mathrm{POCCR} * m a r a)$ \\
\hline PKb-Hp-K1 & *mara & (PAN/PUCLR "mara) \\
\hline 28. *lel & $\begin{array}{l}\text { 'siang' } \\
\text { *lel }\end{array}$ & $(\mathrm{PAN} / \mathrm{PPHZC} * l a l)$ \\
\hline 29. *let & 'jauh' & $(\mathrm{PAN} / \mathrm{PNPNPAWC} * l a a)$ \\
\hline 30. ${ }^{*}{ }_{\text {tan }}^{\text {PKb-Hp-Kl }}$ & $\begin{array}{l}\text { *let } \\
\text { 'laut' } \\
\text { *tan }\end{array}$ & $(\mathrm{PAN} / \mathrm{D} * t a t)$ \\
\hline 31. *ma & 'datang' & $(\mathrm{PAN} / \mathrm{C} * m a i)$ \\
\hline $\begin{array}{l}\text { PKb-Hp-K1 } \\
\text { 32. *kelelen } \\
\text { PKb-Hp-K1 }\end{array}$ & $\begin{array}{l}\text { *ma } \\
\text { 'laba-laba' } \\
\text { *kelelen }\end{array}$ & (PAN/C *kelewelewe) \\
\hline $\begin{array}{l}\text { 33. *luliy } \\
\text { Pkb-Hp-K1 }\end{array}$ & $\begin{array}{l}\text { 'luar' } \\
\text { *luliq }\end{array}$ & $(\mathrm{PAN} / \mathrm{PPHZF} * l u a \eta)$ \\
\hline $\begin{array}{l}\text { 34. }{ }^{*} p u \\
\quad \text { PKb-Hp-K1 }\end{array}$ & $\begin{array}{l}\text { 'meniup' } \\
\text { *pu }\end{array}$ & $(\mathrm{PAN} / \mathrm{C} * p u t)$ \\
\hline $\begin{array}{l}\text { 35. *do } \\
\quad \mathrm{PKb}-\mathrm{Hp}-\mathrm{Kl}\end{array}$ & $\begin{array}{l}\text { 'telur' } \\
\text { *do }\end{array}$ & $(\mathrm{PAN} / \mathrm{DLO} *$ nato $)$ \\
\hline
\end{tabular}

Beberapa contoh etimon $\mathrm{PKbHpKl}$ di atas menampakkan turunan dari Proto Austronesia (PAN) yang disusun oleh penemunya setelah garis miring (/).

\section{Pantulan (refleks) Proto Austronesia (PAN)}

Kajian ini membahas tentang pantulan (refleks) Proto Austronesia (PAN) ke Protobahasa Kabola, Protobahasa Hamap, dan Protobahasa Klon (PKbHpKl). Penelusuran mengenai hubungan Proto Austronesi (PAN) terhadap protobahasa Kabola, protobahasa Hamap dan protobahasa Klon ( $\mathrm{PKbHpKl}$ ) berpedoman pada kajian hasil rekonstruksi PAN yang disusun oleh beberapa ahli bidang studi linguistik Austronesia seperti: Demwolff, Dyen, Blust, Lopez, serta paraahli lainnya (Wurm dan Wilson, 1978:xviii; band Budasi, 2007). Pantulan (refleks) fonem vokal PAN pada $\mathrm{PKbHpKl} \mathrm{sebagai} \mathrm{berikut.}$

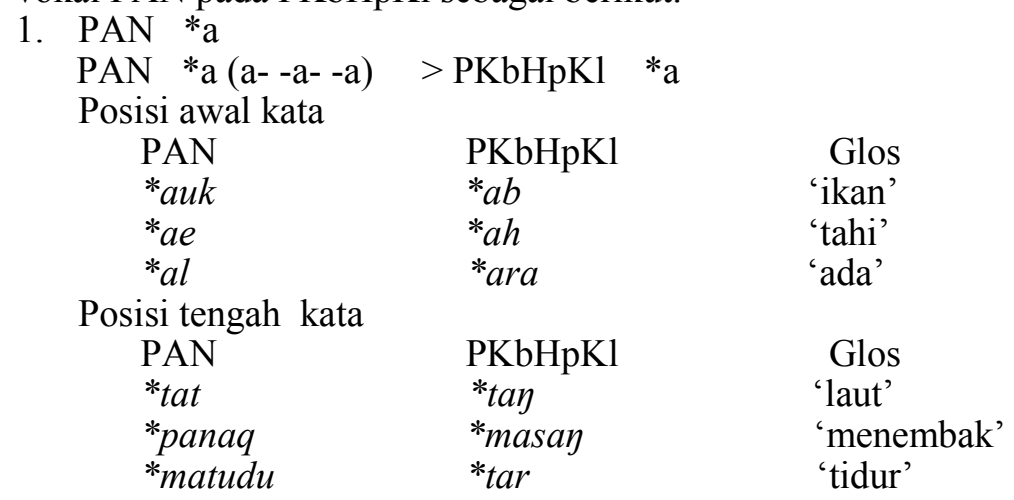


Vol. 1, No. 1, Juli 2017, 39

Available Online at https://ejournal.warmadewa.ac.id/index.php/kulturistik

DOI: dx.doi.org/10.22225/kulturistik.1.1.215

Posisi akhir kata

$\begin{array}{lll}\text { PAN } & \text { PKbHpK1 } & \text { Glos } \\ \text { *mima }_{\text {mima }} & *_{\text {na }} & \text { 'minum' } \\ \text { *ma' } i^{\text {* }} & \text { *ma }_{\text {mara }} & \text { 'datang' } \\ \text { * }_{\text {sura }} & \text { * }_{\text {sura }} & \text { 'surat' }\end{array}$

2. PAN *i

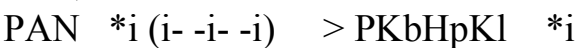

Posisi awal kata

$\begin{array}{ll}\text { PAN } & \text { PKbHpK1 } \\ \text { *ijuy }_{\text {iju }} & *_{\text {il } i l} \\ \text { *iput }_{\text {iofa }} & *_{\text {ihi }} \\ \text { *iomo }\end{array}$

Glos

'burung nuri'

'kotoran binatang'

'manusia'

Posisi tengah kata

$\begin{array}{ll}\text { PAN } & \text { PKbHpK1 } \\ \text { *bibi } & \text { *kib } \\ \text { *rie } & \text { *miorok }^{\text {mil }} \\ \text { *kuil } & \text { *poil }^{\text {pro }}\end{array}$

Glos

'kambing'

'kedua kali'

Posisi akhir kata

$\begin{array}{lll}\text { PAN } & \text { PKbHpK1 } & \text { Glos } \\ \text { *wii } & \text { *mogoi } & \text { 'mangga' } \\ \text { *kalihi } & \text { *gelagai } & \text { 'menemukan' } \\ \text { *pelahui } & \text { *pelay ei } & \text { 'kapal' }\end{array}$

3. $\mathrm{PAN} * \mathrm{u}$

PAN *u (u- -u- -u) > PKbHpKl *u

Posisi awal kata

$\begin{array}{lll}\text { PAN } & \text { PKbHpK1 } & \text { Glos } \\ \text { *ulan } & *_{u l} & \text { 'bulan' } \\ \text { *ut } & *_{u t} & \text { 'empat' } \\ \text { *ural } & *_{\text {ural }} & \text { 'gerhana' }\end{array}$

Posisi tengah kata

\begin{tabular}{|c|c|c|}
\hline PAN & PKbHpK1 & Glos \\
\hline *tunu & $* t u t$ & 'hangat' \\
\hline *bukid & *buk & 'gunung' \\
\hline $\begin{array}{l}\text { *quta } \\
\text { sisi akhir kata }\end{array}$ & *buh & 'belukar' \\
\hline PAN & PKbHpK1 & Glos \\
\hline *ratu & *ratmu & 'seratus' \\
\hline *ta?u & *tuu & 'tahun' \\
\hline
\end{tabular}

4. PAN *e

PAN *e (e- -e- -e) > PKbHpKl *e

Posisi awal kata

$\begin{array}{ll}\text { PAN } & \text { PKbHpK1 } \\ \text { *ebay } & \text { *ebay } \\ \text { *elof } & \text { *esah } \\ \text { *eqaybay } & \text { *eharoy } \\ \text { isi tengah kata } & \\ \text { PAN } & \text { PKbHpK1 } \\ \text { *galepi } & \text { *lel } \\ \text { *belt } & \text { *beh }\end{array}$

Glos

'desa'

'mengasihi'

'serong'

Glos

'cahaya'

'pukul' 
Vol. 1, No. 1, Juli 2017, 40

Available Online at https://ejournal.warmadewa.ac.id/index.php/kulturistik

DOI: dx.doi.org/10.22225/kulturistik.1.1.215

\begin{tabular}{|c|c|c|}
\hline \multicolumn{3}{|l|}{ Posisi akhir kata } \\
\hline PAN & PKbHpKl & Glos \\
\hline *rie & *miorok & 'kedua kali' \\
\hline$* a e$ & $* a h$ & 'tahi' \\
\hline \multicolumn{3}{|l|}{ PAN $*_{0}$} \\
\hline PAN $*_{0}(0--0--o)$ & $>\mathrm{PKbHpKl} \quad *_{\mathrm{O}}$ & \\
\hline \multicolumn{3}{|l|}{ Posisi awal kata } \\
\hline PAN & PKbHpKl & Glos \\
\hline *ona & *odi & 'jika' \\
\hline \multicolumn{3}{|l|}{ Posisi tengah kata } \\
\hline PAN & PKbHpKl & Glos \\
\hline *adowa & *kobo & 'istri' \\
\hline *toravat & *tidorok & 'delapan' \\
\hline \multicolumn{3}{|l|}{ Posisi akhir kata } \\
\hline PAN & PKbHpKl & Glos \\
\hline *nato & $* d o$ & 'telur' \\
\hline *do'o & *do'o & 'merebus' \\
\hline *teho & *ho & 'tiba' \\
\hline
\end{tabular}

Fonem vokal PAN yakni : $*_{\mathrm{a}}, *_{\mathrm{i}}, *_{\mathrm{u}}, *_{\mathrm{e}}$, dan $*_{\mathrm{o}}$ memiliki posisi lengkap, baik pada posisi awal, tengah, dan akhir seperti pada PKbHpKl. Demikian pula fonem vokal PAN tersebut menampakkan ultima terpantul secara langsung dan teratur seperti pada fonem vokal PKbHpKl. Pantulan (refleks) deret vokal PAN pada $\mathrm{PKbHpKl}$ sebagai berikut.

$\begin{array}{llc}\text { PAN } & \text { PKbHpKl } & \text { Glos } \\ \text { *ta? } u & \text { *tuu } & \text { 'tahun' } \\ \text { *niu } & \text { *niu } & \text { 'kata' } \\ \text { *uok } & \text { *uok } & \text { "baik' }\end{array}$

Deret vokal PAN pada data di atas tidak menampakkan pantulan secara langsung terhadap PKbHpKl, kecuali deret vokal *uu, $\boldsymbol{i} \boldsymbol{u}$, dan $\boldsymbol{u}$.

Pantulan (refleks) fonem konsonan PAN pada PKbHpKl sebagai berikut.

1. PAN *b

PAN *b (b- -b- -b) > PKbHpKl *b

Posisi awal kata

$\begin{array}{lll}\text { PAN } & \text { PKbHpKl } & \text { Glos } \\ \text { *boo } & \text { *boi } & \text { 'babi' } \\ \text { *bukuhl } & \text { *buh } & \text { 'belukar' } \\ \text { isi tengah kata } & & \\ \text { PAN } & \text { PKbHpKl } & \text { Glos } \\ \text { *babalay } & \text { *babail } & \text { 'belalang', } \\ \text { *tabak } & \text { *abak } & \text { 'tembakau' }\end{array}$

Posisi akhir kata

$\begin{array}{lll}\text { PAN } & \text { PKbHpK1 } & \text { Glos } \\ * l u b & * l u b & \text { 'domba' } \\ \text { *kib } & \text { *kib } & \text { 'kambing' } \\ \text { *uwereb } & \text { *uwereb } & \text { 'dengar' }\end{array}$


Vol. 1, No. 1, Juli 2017, 41

Available Online at https://ejournal.warmadewa.ac.id/index.php/kulturistik

DOI: dx.doi.org/10.22225/kulturistik.1.1.215

Fonem konsonan PAN yakni : *b memiliki posisi lengkap, baik pada posisi awal, tengah, maupun akhir seperti pada PKbHpKl. Demikian pula fonem konsonan PAN tersebut menampakkan ultima terpantul secara langsung dan teratur seperti pada fonem konsonan PKbHpKl.

2. PAN *p

PAN *p (p- -p- -p) > PKbHpKl *p

Posisi awal kata

$\begin{array}{lcc}\text { PAN } & \text { PKbHpKl } & \text { Glos } \\ \text { *pal } & \text { *pol ai } & \text { 'palu' }\end{array}$

Posisi tengah kata

$\begin{array}{lll}\text { PAN } & \text { PKbHpKl } & \text { Glos } \\ \text { *gipo } & \text { *gopot } & \text { 'paha' } \\ \text { *kupay } & \text { *tapay } & \text { 'tumb }\end{array}$

Posisi akhir kata

$\begin{array}{lcc}\text { PAN } & \text { PKbHpKl } & \text { Glos } \\ \text { *mahip }^{\text {*mahip }} & \text { 'rasa' } \\ \text { *sedep } & \text { *ap }^{\text {a }} & \text { 'kapas' }\end{array}$

Fonem konsonan PAN yakni : *p memiliki posisi lengkap, baik pada posisi awal, tengah, maupun akhir seperti pada PKbHpKl. Demikian pula fonem konsonan PAN tersebut menampakkan ultima terpantul secara langsung dan teratur seperti pada fonem konsonan $\mathrm{PKbHpKl}$.

3. PAN *m

PAN *m (m- -m- -m) > PKbHpKl *m

Posisi awal kata

$\begin{array}{lcc}\text { PAN } & \text { PKbHpKl } & \text { Glos } \\ \text { *ma }_{m a} & \text { 'kucing' }\end{array}$

Posisi tengah kata

PAN

*gominok

*namalak

*kejumi

*kumuke

Posisi akhir kata

$\begin{array}{ll}\text { PAN } & \text { PKbHpKl } \\ \text { *wom } & \text { *wom } \\ \text { *lakam } & \text { *lam } \\ \text { *doro'om } & \text { *doro'om }\end{array}$

PKbHpKl Glos

*gominok 'setia'

*namalak 'burung merpati'

*gumuni 'ciuman'

*kumuke 'bodoh'

Fonem konsonan PAN yakni : *m memiliki posisi lengkap, baik pada posisi awal, tengah, maupun akhir seperti pada PKbHpKl. Demikian pula fonem konsonan PAN tersebut menampakkan ultima terpantul secara langsung dan teratur seperti pada fonem konsonan PKbHpKl.

4. PAN *n

PAN *n (n- -n- -n) > PKbHpKl $\quad *_{n}$

Posisi awal kata

$\begin{array}{lcc}\text { PAN } & \text { PKbHpKl } & \text { Glos } \\ \text { *nome } & \text { *nome }^{\text {nome }} & \text { 'dandang, } \\ \text { *nepa } & \text { *nepa }^{\text {nepa }} & \text { 'jari kaki' }\end{array}$


Vol. 1, No. 1, Juli 2017, 42

Available Online at https://ejournal.warmadewa.ac.id/index.php/kulturistik

DOI: dx.doi.org/10.22225/kulturistik.1.1.215

Posisi tengah kata

PAN

*nunok

*gominok

*tinaak

Posisi akhir kata

PAN

*men

*arahain
$\mathrm{PKbHpKl}$

*nunok

*gominok

*tinaak

PKbHpKl

*men

*arahain
Glos

'bagus'

'setia'

'menipu'

Glos

'rumput'

'memaki'

Fonem konsonan PAN yakni : *n memiliki posisi lengkap, baik pada posisi awal, tengah, maupun akhir seperti pada PKbHpKl. Demikian pula fonem konsonan PAN tersebut menampakkan ultima terpantul secara langsung dan teratur seperti pada fonem konsonan $\mathrm{PKbHpKl}$.

5. PAN *1

PAN *1 (1- -1- -1) > PKbHpKl *1

Posisi awal kata

$\begin{array}{lll}\text { PAN } & \text { PKbHpKl } \\ \text { *laklak } & \text { *leki } & \text { Glos } \\ \text { PAN tengah kata } & & \text { 'karang' } \\ \text { *yalai } & \text { PKbHpKl } & \\ \text { *malei } & \text { Glos } \\ \text { PAN } & & \text { 'air liur' } \\ \text { *dul } & \text { PKbHpK1 } & \\ \text { *lal } & \text { *dul } & \text { Glos } \\ \text { *fadol } & \text { *lal } & \text { 'lagu' } \\ \text { *fadol } & \text { 'bubur' }\end{array}$

Fonem konsonan PAN yakni : *1 memiliki posisi lengkap, baik pada posisi awal, tengah, maupun akhir seperti pada PKbHpKl. Demikian pula fonem konsonan PAN tersebut menampakkan ultima terpantul secara langsung dan teratur seperti pada fonem konsonan $\mathrm{PKbHpKl}$.

6. PAN *g

PAN $*_{\mathrm{g}}(\mathrm{g}-$-g- $\mathrm{g}) \quad>\mathrm{PKbHpKl} \quad *_{\mathrm{g}}$

Posisi awal kata

$\begin{array}{lcc}\text { PAN } & \text { PKbHpKl } & \text { Glos } \\ \text { *gominok } & \text { *gominok } & \text { 'setia' } \\ \text { *grawad } & \text { 'gariay } & \text { 'asuh' } \\ \text { isi tengah kata } & & \text { Glos } \\ \text { PAN } & \text { PKbHpKl } & \text { *bagai } \\ \text { *bugaya } & \text { *mogoi } & \text { 'buaya' } \\ \text { *mogoi } & & \text { 'mangga' } \\ \text { isi akhir kata } & \text { PKbHpKl } & \\ \text { PAN } & \text { *tofag } & \text { Glos } \\ \text { *tofag } & \text { *lakiag } & \text { 'kacang' } \\ \text { *lakiag } & \text { 'tupai' }\end{array}$

Fonem konsonan PAN yakni : *g memiliki posisi lengkap, baik pada posisi awal, tengah, maupun akhir seperti pada PKbHpKl. Demikian pula fonem konsonan PAN tersebut menampakkan ultima terpantul secara langsung dan tera- 
tur seperti pada fonem konsonan $\mathrm{PKbHpKl}$.

7. PAN *k

PAN *k (k- -k- $\mathrm{k}) \quad>$ PKbHpKl $\quad *_{\mathrm{k}}$

Posisi awal kata

$\begin{array}{llr}\text { PAN } & \text { PKbHpKl } & \text { Glos } \\ \text { *kuykil } & \text { *kadelay } & \text { 'saku' } \\ \text { *kapala } & \text { *kapala } & \text { 'kapal' }\end{array}$

Posisi tengah kata

$\begin{array}{ll}\text { PAN } & \text { PKbHpKl } \\ \text { *payku } & \text { *biyku } \\ \text { *kanuke } & \text { *kanuke } \\ \text { *deko } & \text { *deko } \\ \text { *duke } & \text { *duke }\end{array}$

Glos

'pacul'

'bodoh'

isi akhir kata

$\begin{array}{ll}\text { PAN } & \text { PKbHpK1 } \\ \text { * salak }_{\text {*kalak }} & \text { *kik } \\ \text { *gotabak } & \text { *kik } \\ \text { *gotabak }\end{array}$

'celana'

'cungkil'

Fonem konsonan PAN yakni : *k memiliki posisi lengkap, baik pada posisi awal, tengah, maupun akhir seperti pada PKbHpKl. Demikian pula fonem konsonan PAN tersebut menampakkan ultima terpantul secara langsung dan teratur seperti pada fonem konsonan $\mathrm{PKbHpKl}$.

8. PAN *h

PAN *h (h- -h- -h) $\quad>$ PKbHpKl *h

Posisi awal kata

$\begin{array}{ll}\text { PAN } & \text { PKbHpKl } \\ \text { *hinih } & \text { *haoni } \\ \text { *hul ana } & \text { *hul ana }\end{array}$

Posisi tengah kata
PAN
*sahoir
*nahan

Posisi akhir kata

$\begin{array}{ll}\text { PAN } & \text { PKbHpKl } \\ \text { *temuh } & \text { *tuku mih } \\ \text { *dulah } & \text { *bah }\end{array}$

Glos

'di sini'

'huruf'

Glos

'mengeluh'

'mencuci'

Glos

'berjumpa'

'luka'

Fonem konsonan PAN yakni : ${ }^{*}$ h memiliki posisi lengkap, baik pada posisi awal, tengah, maupun akhir seperti pada $\mathrm{PKbHpKl}$. Demikian pula fonem konsonan PAN tersebut menampakkan ultima terpantul secara langsung dan teratur seperti pada fonem konsonan PKbHpKl.

9. $\mathrm{PAN} * \mathrm{t}$

PAN *t $(\mathrm{t}-\mathrm{-t}-\mathrm{t}) \quad>$ PKbHpKl $\quad *_{\mathrm{t}}$

Posisi awal kata

$\begin{array}{lcc}\text { PAN } & \text { PKbHpK1 } & \text { Glos } \\ \text { *tay } & \text { *tay } & \text { 'laut' } \\ \text { *tikor } & \text { *tikor } & \text { 'barat' } \\ \text { *taka } & * \text { taka } & \text { 'curi' }\end{array}$


Vol. 1, No. 1, Juli 2017, 44

Available Online at https://ejournal.warmadewa.ac.id/index.php/kulturistik

DOI: dx.doi.org/10.22225/kulturistik.1.1.215

Posisi tengah kata

PAN

*bates

Posisi akhir kata

PAN

*dat

*awit

*pet
$\mathrm{PKbHpKl}$

$*_{\text {watas }}$

$\mathrm{PKbHpKl}$

*dat

*awit

*pet
Glos

'batas'

Glos

'cucu'

'hamil'

'jambu'

Fonem konsonan PAN yakni : *t memiliki posisi lengkap, baik pada posisi awal, tengah, maupun akhir seperti pada PKbHpKl. Demikian pula fonem konsonan PAN tersebut menampakkan ultima terpantul secara langsung dan teratur seperti pada fonem konsonan PKbHpKl. Pantulan (refleks) deret konsonan PAN pada PKbHpKl sebagai berikut.

$\begin{array}{ll}\text { PAN } & \text { PKbHpK1 } \\ \text { 1) *dilbut } & \text { *dilbut } \\ \text { 2) *apsah } & \text { *apsah } \\ \text { 3) *tanfal } & \text { *tanfal } \\ \text { 4)*lollap } & \text { *lollap } \\ \text { 5)*horlap } & \text { *horlap }\end{array}$

Glos

'kebun'

'kapas'

'utusan'

'menuai'

'pungut'

Deret konsonan PAN pada data no 1) sampai 5) di atas menampakkan pantulan secara langsung terhadap PKbHpK1. Pantulan (refleks) gugus konsonan PAN pada PKbHpKl sebagai berikut.
PAN
1) * gyar
2) * gyedok
$\mathrm{PKbHpKl}$
*gyar
*gyedok
Glos
'bibi'
'lubang pantat'

Gugus konsonan PAN pada data di atas menampakkan pantulan secara langsung terhadap PKbHpKl. Dengan demikian, gugus konsonan PAN ditemukan seperti pada gugus konsonan $\mathrm{PKbHpK1}$.

\section{SIMPULAN}

Daftar etimon protobahasa Kabola, protobahasa Hamap, dan protobahasa Klon (PKbHpKl) menampakkan turunan dari Proto Austronesia (PAN) yang disusun oleh penemunya setelah garis miring (/). Pantulan (refleks) PAN ke Protobahasa Kabola, Protobahasa Hamap, dan Protobahasa Klon ( $\mathrm{PKbHpKl})$ ditemukan refleks fonem vokal PAN, deret vokal PAN, fonem konsonan PAN, dan gugus konsonan PAN pada PKbHpKl. Pantulan (refleks) fonem PAN pada $\mathrm{PKbHpKl}$ ditemukan berupa pantulan (refleks) fonem vokal PAN yakni : *a, *i, $*_{\mathrm{u}},{ }_{\mathrm{e}}$, dan ${ }^{*}$ o memiliki posisi lengkap, baik pada posisi awal, tengah, maupun akhir seperti pada PKbHpKl. Dengan demikian, fonem vokal PAN tersebut menampakkan ultima terpantul secara langsung dan teratur seperti pada fonem vokal PKLbHpKl. Deret vokal PAN tidak menampakkan pantulan secara langsung terhadap PKbHpKl, kecuali deret vokal *uu, *iu, dan *uo. Fonem konsonan PAN yakni : *b, ${ }^{*} \mathrm{p},{ }^{*} \mathrm{~m},{ }^{*} \mathrm{n}, 1,{ }^{*} \mathrm{~g},{ }^{*} \mathrm{k},{ }^{*} \mathrm{~h}$, dan ${ }^{*} \mathrm{t}$ memiliki posisi lengkap, baik pada posisi awal, tengah, maupun akhir seperti pada PKbHpKl. Demikian pula fonem konsonan PAN tersebut menampakkan ultima terpantul secara langsung dan teratur seperti pada fonem konsonan PKbHpKl. Deret Konsonan PAN yakni: *lb, 
*ps, *yt, *11, dan *rl menampakkan pantulan secara langsung terhadap PKbHpKl. Gugus konsonan PAN yakni *gy menampakkan pantulan secara langsung terhadap $\mathrm{PKbHpKl}$. Beberapa fonem yang terpantul dari Proto PAN ke protobahasa Kabola, protobahasa Hamap, dan protobahasa Klon menunjukkan bahwa ketiga bahasa tersebut merupakan turunan dari Proto PAN serta tergolong bahasa Austronesia.

\section{DAFTAR PUSTAKA}

Adelaar, A., \& P, H. N. (2005). The Austronesian languages of A sia and Madagascar. London and New York: Routledge.

Ayatrohaedi. (1979). Dialektologi: sebuah pengantar. Jakarta: Pusat Pembinaa dan Pengembangan Bahasa Departemen Pendidikan dan Kebudayaan.

Bellwood, P., J.Fox, J., \& Tryon., D. (1995). The Austronesian: historical and comparative perspectives. Canberra: ANU Printing Service.

Budasi, I. G. (2007). Kekerabatan bahasa-bahasa di Sumba (suatu kajian linguistik historis komparatif). Universitas Gadjah Mada.

Bungin. (2008). Penelitian kualitatif. Jakarta: Prenada Media Group.

Chomsky, N. (2000). New horizons in the study of language and mind. Cambridge: Cambridge University Press.

Danandjaya, J. (1994). Foklor Indonesia, ilmu gosip, dongeng dan lain-lain. Jakarta: PT Temrit.

Djajasudarma, T. F. (1993). Metode linguistik: ancangan metode penelitian dan kajian. Bandung: Eresco.

Fernandez, I. Y. (1996). Relasi historis kekerabatan bahasa Flores. kajian linguistik historis komparatif terhadap sembilan bahasa di Flores. Jakarta: PT Nusa Indah.

Ino, L. (2013). Protobahasa Modebur, Kaera, dan Teiwa, bahasa kerabat non Austronesia di pulau Pantar Nusa Tenggara Timur. Universitas Udayana.

Keraf, G. (1990). Linguistik bandingan tipologis. Jakarta: PT Gramedia.

Mandala, H. (1999). Pengelompokan genetis bahasa Karui, Waimoa, dan Naueti di Timor Timur. Universitas Udayana.

Mashun. (2007). Metode penelitian bahasa: tahapan strategi, metode, dan tekniknya. Jakarta: PT aja Grafindo Persada.

McMahon, A. M. S. (1999). Understanding language change. Cambridge: University Of Cambridge.

Muhajir. Noeng H. (1996). Metodelogi penelitian kualitatif. Bandung: PT Remaja Kosada Karya.

Samarin, W. J. (1998). Ilmu bahasa lapangan. Yogyakarta: Kanisius.

Sudaryanto. (1986). Metode linguistik. Yogyakarta: Gadjah Mada University Press.

Suryati, N. M. (2012). Variasi fonologis dan leksikal bahasa Lio di Flores, Nusa Tenggara Timur: kajian dialek geografi. Universitas Udayana.

Syamsudin, A. R. (1996). Kelompok bahasa Bima-Sumba. Kajian linguistik historis komparatif. Unpad. 